Research Article

\title{
Comparison of Creep Properties of Cast and Wrought Haynes 282 Superalloy
}

\author{
Young-Joo Kim, ${ }^{1}$ Jae-Hyeun Park, ${ }^{2}$ and Yong-Sik Ahn $\mathbb{D}^{1}$ \\ ${ }^{1}$ Department of Materials Science \& Engineering, Pukyong National University, Busan, Republic of Korea \\ ${ }^{2}$ Research Institute of Industrial Science \& Technology, Pohang, Republic of Korea \\ Correspondence should be addressed to Yong-Sik Ahn; ysahn@pknu.ac.kr
}

Received 2 August 2017; Revised 2 November 2017; Accepted 25 December 2017; Published 14 February 2018

Academic Editor: Santiago Garcia-Granda

Copyright (C) 2018 Young-Joo Kim et al. This is an open access article distributed under the Creative Commons Attribution License, which permits unrestricted use, distribution, and reproduction in any medium, provided the original work is properly cited.

\begin{abstract}
Ni-based superalloy Haynes 282 was developed as a gas turbine material for use in the ultra-supercritical (USC) stage of nextgeneration coal-fired power plants. Temperatures in the USC stage exceed $700^{\circ} \mathrm{C}$ during operation. Despite the important role of Haynes 282 in increasing the performance of high-pressure turbines, as a result of its high-temperature capability, there is little information on the microstructure, deformation mechanism, or mechanical properties of the cast condition of this alloy. In this study, we compared the creep properties of Haynes 282 cast alloy with those of its wrought alloy counterpart. The tensile test results of cast and wrought Haynes 282 alloys over the temperature range $25-800^{\circ} \mathrm{C}$ showed that the cast product exhibited significantly lower strength and ductility compared with the wrought product at all test temperatures. A creep test performed at $750^{\circ} \mathrm{C}$ showed only a slight difference in the rupture life of the two products. Based on the creep test results, the deformation mechanism is discussed.
\end{abstract}

\section{Introduction}

Haynes 282 alloy is a promising Ni-based superalloy for the gas turbines of next-generation coal-fired power plants operating in the ultra-supercritical (USC) stage at temperatures that exceed $700^{\circ} \mathrm{C}$. This alloy, developed for extreme heat resistance by Haynes International, shows excellent strength at high temperatures, due to solidsolution strengthening and $\gamma^{\prime}$-precipitation strengthening of its matrix. Compared with Waspaloy, a commonly used high-temperature alloy, Haynes 282, offers superior machinability and responds well to heat treatment, due to the lower fraction of the $\gamma^{\prime}$-phase. Haynes 282 alloy has excellent creep strength, especially in the temperature range $649-927^{\circ} \mathrm{C}[1-3]$. Although this alloy is used primarily as a wrought alloy, its cast form would be advantageous for power plant applications. Casings are one of many assemblies used in advanced-USC (A-USC) coal-fired power plants and are appropriate for use after casting without any plastic working.
In this study, to investigate the applicability of cast Haynes 282 alloy as a casing material, the alloy was fabricated using a permanent casting process. Cast and wrought alloy samples were heat-treated under the same conditions. The microstructures of the wrought and cast forms were analysed and compared. Tensile tests were performed over the temperature range $20-800^{\circ} \mathrm{C}$, and creep tests were conducted at $750^{\circ} \mathrm{C}$.

\section{Methodology}

Tensile test samples of the wrought alloy were machined from a Haynes 282 alloy plate produced by Haynes International. For the Haynes 282 cast alloy samples, a $260 \times 260 \times 300 \mathrm{~mm}^{3}$ tetragonal cylinder-type ingot $(170 \mathrm{~kg})$ was prepared via vacuum induction melting by a casting manufacturer. Table 1 lists the alloy composition of Haynes 282. The wrought and cast alloys were heat-treated by solution annealing at $1,121-1,177^{\circ} \mathrm{C}$ for $45 \mathrm{~min}$, followed by water quenching and a consecutive two-step ageing process. The two-step ageing 
TABLE 1: Chemical composition (wt.\%) of Haynes 282 alloy.

\begin{tabular}{lccccccccc}
\hline & $\mathrm{Cr}$ & $\mathrm{Co}$ & $\mathrm{Mo}$ & $\mathrm{Ti}$ & $\mathrm{Al}$ & $\mathrm{Fe}$ & $\mathrm{Mn}$ & $\mathrm{Si}$ & $\mathrm{C}$ \\
\hline Wrought & 19.55 & 10.32 & 8.52 & 2.23 & 1.48 & 0.84 & 0.06 & 0.05 & 0.061 \\
Cast & 19.98 & 10.06 & 8.76 & 2.15 & 1.42 & 0.5 & 0.08 & 0.12 & 0.048 \\
\hline
\end{tabular}
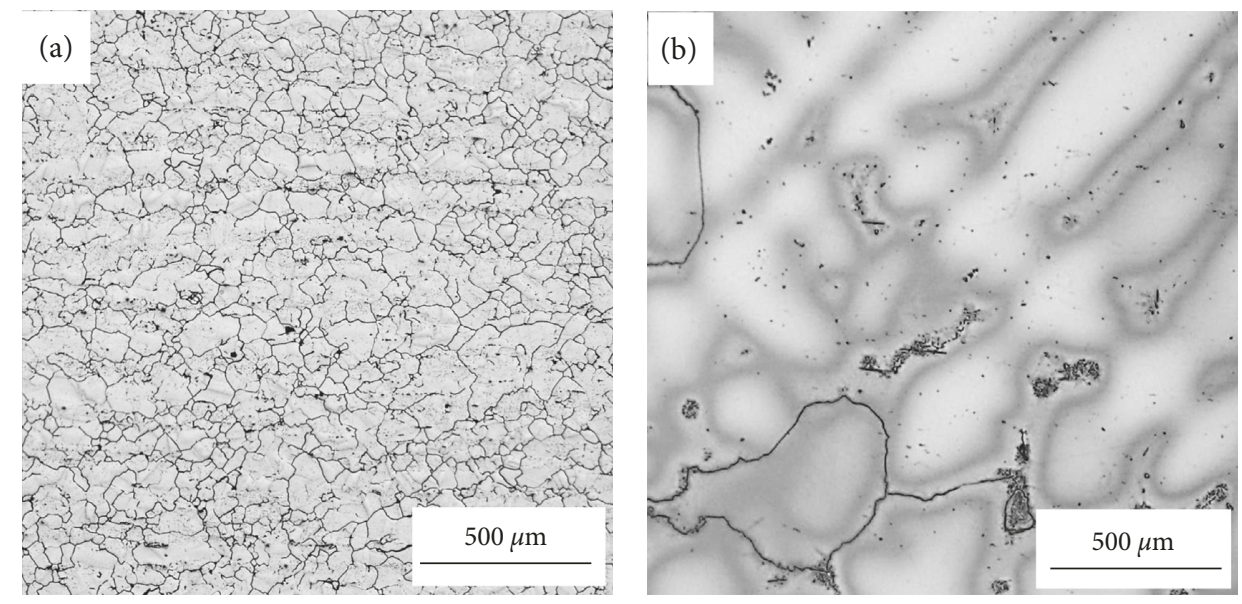

Figure 1: Optical microstructures of Haynes 282 (a) wrought and (b) cast alloys.

treatment consisted of heat treatment at $1,010^{\circ} \mathrm{C}$ for $2 \mathrm{~h}$, followed by heat treatment at $788^{\circ} \mathrm{C}$ for $8 \mathrm{~h}$, for optimal distribution and size development of $\gamma^{\prime}$ precipitates [4]. The ageing treatments were followed by air cooling. Tensile-tested specimens of the wrought alloy were machined parallel to the longitudinal direction (gauge diameter: $6 \mathrm{~mm}$; gauge length: $30 \mathrm{~mm}$ ). The cast alloy specimens were machined from the centre part of the ingot to minimise the anisotropic effect of the cast microstructure. A room-temperature tensile test was conducted at a constant crosshead speed of $1.5 \mathrm{~mm} / \mathrm{min}$; tensile tests at higher temperatures $\left(>200^{\circ} \mathrm{C}\right)$ used a crosshead speed of $0.125 \mathrm{~mm} / \mathrm{min}$.

Creep experiments were conducted using a constantload creep tester (lever ratio: $20: 1$ ) and a round specimen (gauge diameter: $6 \mathrm{~mm}$; gauge length: $27 \mathrm{~mm}$; grip diameter: $32 \mathrm{~mm}$ ). The creep test was conducted in air at $750^{\circ} \mathrm{C}$ over the stress range $300-400 \mathrm{MPa}$. The temperature was controlled within $\pm 2^{\circ} \mathrm{C}$ along the gauge length of the specimen during the creep test. Elongation of the creep specimens was monitored by an extensometer.

Metallographic sections, prepared using standard mechanical polishing procedures, were electrolytically etched in an $\mathrm{HNO}_{3}: \mathrm{H}_{2} \mathrm{O}$ solution (volume ratio: $1: 1$ ). A thin foil for transmission electron microscopy (TEM) observation was fabricated with a thickness of $100 \mathrm{~nm}$ using a focused ion beam (FIB) instrument.

\section{Results and Discussions}

3.1. Microstructure. Figure 1 shows optical microstructures of specimens after ageing treatment. The wrought alloy samples exhibited mostly equiaxed grains, with a size of 50-100 $\mathrm{m}$ (Figure 1(a)), while the cast alloy specimens

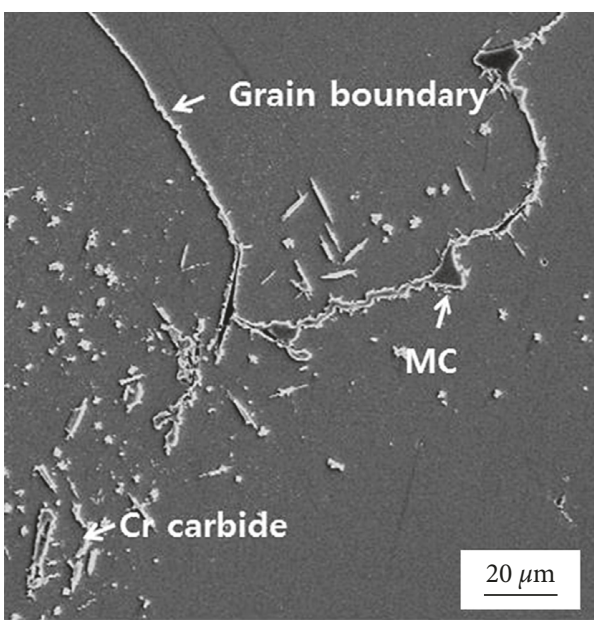

Figure 2: Scanning electron microscopy (SEM) image of cast Haynes 282 after ageing for $8 \mathrm{~h}$.

exhibited a dendritic structure (average thickness: $100 \mu \mathrm{m}$ ) (Figure 1(b)). Because the sample of cast alloy was sectioned from the centre region of the ingot, it was expected to have the equiaxed microstructure; however, the marked dendritic structure was attributed to the slow cooling rate during solidification. Several secondary phases were found in both microstructures, most of which appeared in the interdendritic region of the cast alloy specimen. These precipitates form after solution treatment following quenching. $\gamma^{\prime}$ precipitates were not visible in the optical micrographs due to their small size.

Figure 2 shows scanning electron microscopy (SEM) images of the cast structure after ageing treatment, in which 
various phases were analysed via energy dispersive X-ray spectrometry (EDS). The particles observed in the grain interiors and grain boundaries are MC-type carbides, such as (Ti,Mo)C; Cr-rich carbides (presumably $\mathrm{M}_{23} \mathrm{C}_{6}$ ) precipitated preferentially in interdendritic regions and grain boundaries. Matysiak et al. [5] investigated the cast microstructure of the same alloy and reported that the secondary phases were mostly $(\mathrm{Mo} / \mathrm{Cr})$-rich carbide and the $\gamma^{\prime}$-phase of $(\mathrm{Ni}$, Ti)Al. They also reported that the $\gamma^{\prime}$-phases precipitated as a round shape (size: $70 \mathrm{~nm}$ ) in dendritic regions and as a cubic shape (size: $110 \mathrm{~nm}$ ) in interdendritic regions. The volume fractions of the $\gamma^{\prime}$-phase were $9.6 \%$ and $8.5 \%$ in the dendritic and interdendritic regions, respectively.

Notably, $\sigma$ and (Ti,Mo) ${ }_{2} \mathrm{SC}$ phases were observed in the cast form of the alloy after permanent mould casting; these phases were thought to have formed during the slow solidification process. However, $\sigma$ and $(\mathrm{Ti}, \mathrm{Mo})_{2} \mathrm{SC}$ phases were not observed in our specimens. We investigated the microstructure of the samples after a solutionisation treatment, following a two-step ageing treatment; thus, these phases likely dissolved during solutionisation. The small $\gamma^{\prime}$-phase is not visible in Figure 2 due to insufficient magnification.

3.2. Tensile Test Results. Figure 3 shows stress-strain curves of wrought and cast Haynes 282 alloys based on tensile tests at room temperature. Each test was carried out five times under the same conditions; the results were highly reproducible. In the case of the wrought alloy, the tensile strength (TS) and elongation ranged from 1,010 to $1,035 \mathrm{MPa}$ and $45-48 \%$, respectively. In comparison, the cast alloy had a much lower strength of $460-475 \mathrm{MPa}$ and an elongation of $1.5-1.8 \%$. The cast alloy also exhibited brittle deformation behaviour with low ductility; this was attributed to microcracks and anisotropic and heterogeneous microstructures (e.g., segregation, coarse inclusions, and precipitates) that formed during solidification, as shown in Figure 1. These defects can be eliminated or minimised via hot working processes, such as forging and rolling, in the case of wrought alloy. Coarse inclusions, precipitates, and/or microcracks, at which stress concentrates, drastically reduce the strength and ductility of an alloy by generating fracture cracks in the early stages of loading.

Figure 4 shows the fracture surfaces of the cast and wrought alloys after the tensile tests. The wrought alloy (Figure 4(a)) shows a typical ductile fracture mode, with dimples over the entire fracture surface, whereas the cast alloy (Figure 4(b)) shows two fracture modes over areas consisting of dendritic and interdendritic regions. In the dendritic region, which has a relatively smooth fracture surface, fracture occurred as a result of shearing. In the interdendritic region, cleavage fracture occurred via the fracture of MC carbides and other secondary phase particles. Note the clear transgranular cleavage pattern with facet and flowery cleavages in Figure 4(c) at higher magnification. The dendritic region in Figure 4(c) is not a smooth surface; instead, the surface is covered with many tiny cavities, that is, traces of the $\gamma^{\prime}$-phase in the grain interior.

Figure 5 shows the results of high-temperature tensile tests of cast Haynes 282 alloy compared with data for the

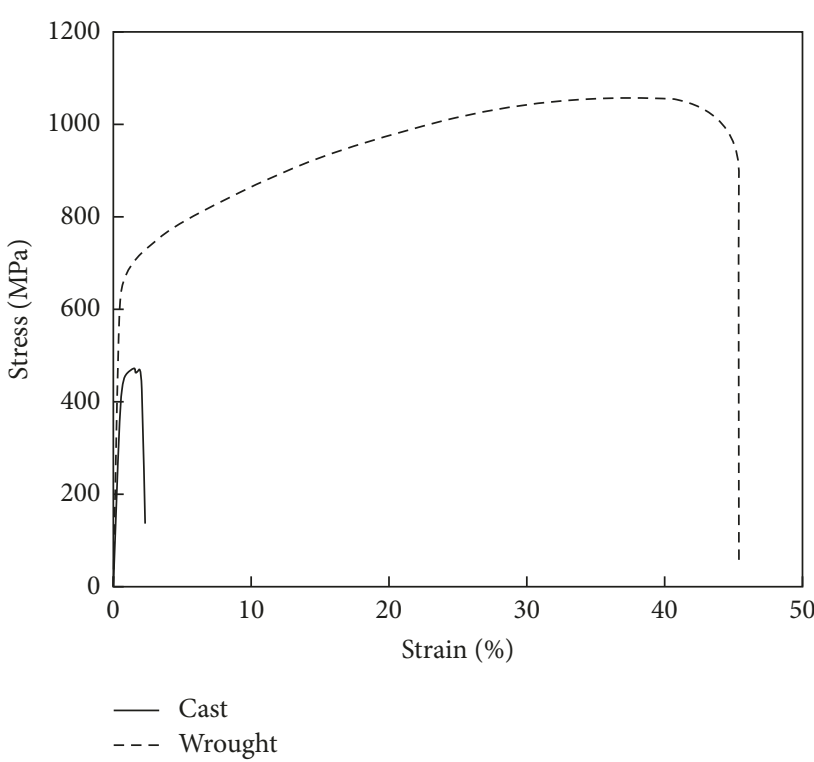

FIgURE 3: Stress-strain curves of wrought and cast Haynes 282 alloys after room-temperature tensile tests.

same alloy under wrought conditions [1]. The hightemperature TS of the wrought alloy dropped sharply at $800^{\circ} \mathrm{C}$ due to thermal activation of dislocations. Under thermal stress, dislocations easily slipped past dislocations $/ \gamma^{\prime}$ precipitates, thus avoiding interaction with the dislocations. In contrast, the TS of the cast alloy sample was not affected significantly by the increase in temperature, showing only a slight reduction, and elongation increased markedly. The cast alloy exhibited brittle behaviour with much lower TS and elongation at both room temperature and high temperature, in contrast to the wrought alloy, which displayed ductile deformation behaviour. In the case of the cast alloy, microcracks generated during casting in the interdendritic region and large secondary phases grew rapidly under tensile stress. With increasing test temperatures up to $800^{\circ} \mathrm{C}$, elongation of the cast alloy increased sharply from $1.5 \%$ to $12.2 \%$. The fracture surface of the cast alloy tested at $800^{\circ} \mathrm{C}$ exhibited a partial dimple fracture, even in the interdendritic region, as shown in Figure 6. The transition from brittle to ductile mode was initiated by thermal activation of dislocations and the slower strain rate at high temperature. The strain rate at high temperature was $0.125 \mathrm{~mm} / \mathrm{min}$, which was much slower than at room temperature $(1.5 \mathrm{~mm} / \mathrm{min})$. The initiation and/or propagation rate of cracks decreased at higher temperature, because the dislocation aggregation, concentrated at large secondary phases or inclusions, was easily relieved, resulting in partial ductile fracture of the cast alloy at $800^{\circ} \mathrm{C}$.

Figure 5 also shows that the TS decreased with increasing test temperature up to $700^{\circ} \mathrm{C}$ and then inversely increased at temperatures between 700 and $750^{\circ} \mathrm{C}$. This anomalous yield behaviour at intermediate temperatures was caused by the strengthening mechanism of $\gamma^{\prime}$-precipitates in Ni-based superalloy [6,7]. Takeuchi and Kuramoto [8] and Paidar et al. [9] reported that the flow stress increases with temperature due to thermally activated cross slip from the $\{111\}$ primary slip plane to the $\{010\}$ cross-slip plane. 


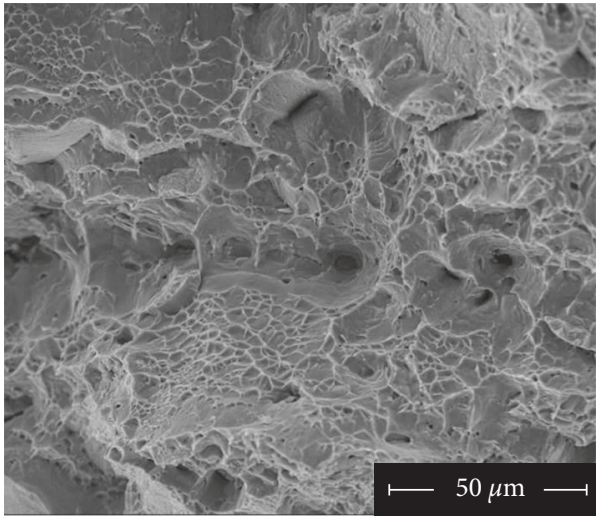

(a)

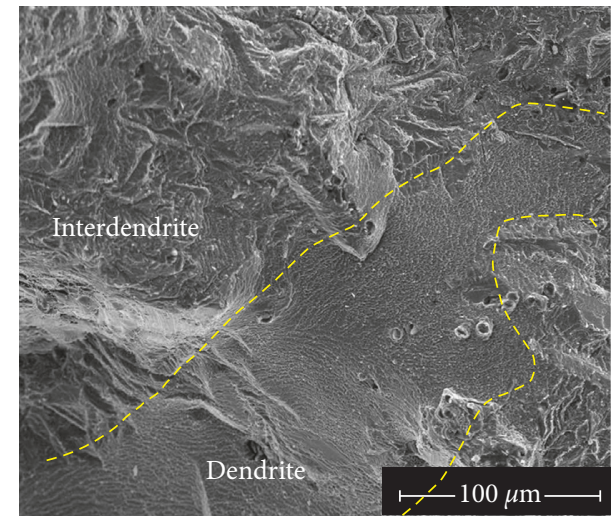

(b)

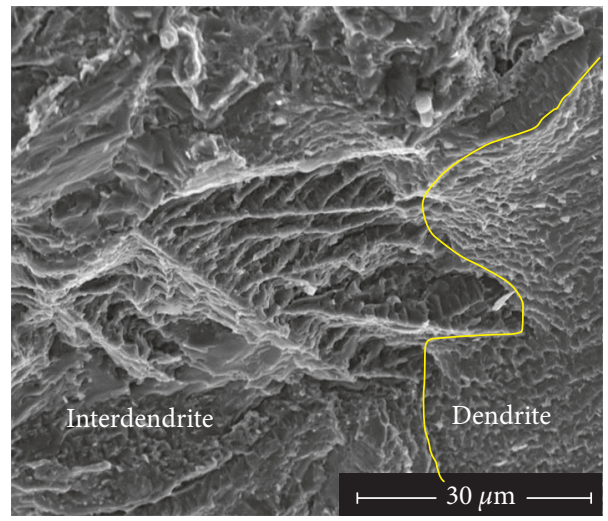

(c)

Figure 4: Fracture surfaces of (a) wrought and (b) cast alloys, and (c) magnified view of the border region between the dendritic and interdendritic regions of the cast alloy after the tensile test at room temperature.

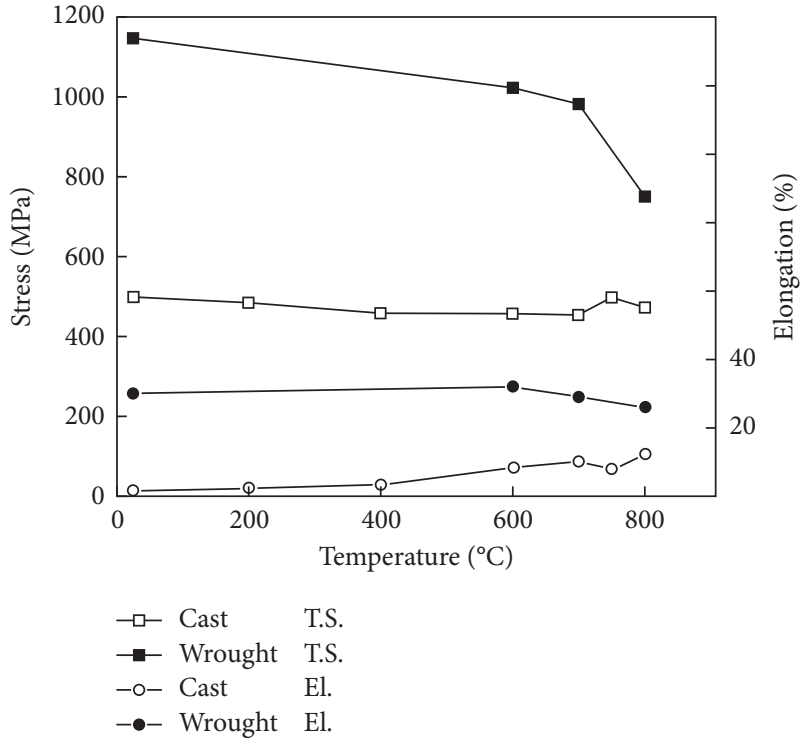

Figure 5: Tensile properties of Haynes 282 cast and wrought alloys at various test temperatures.

3.3. Creep Results. Figure 7 shows the creep curves of cast Haynes 282 alloy at $750^{\circ} \mathrm{C}$; all curves began directly with the secondary (stationary) stage, as opposed to starting with the

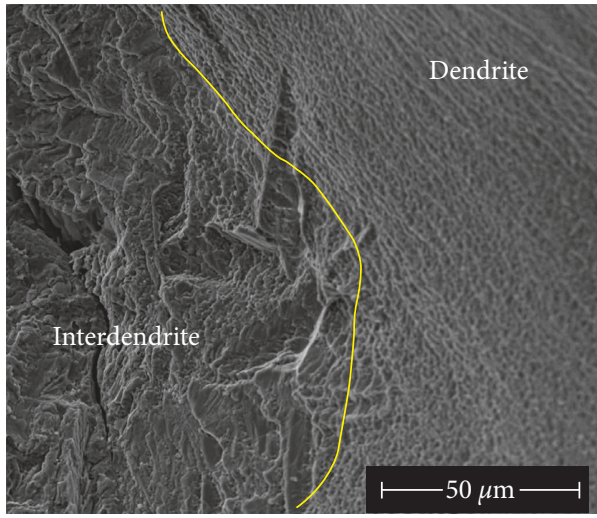

FIgURE 6: Fracture surface of cast alloy after tensile tests at a temperature of $800^{\circ} \mathrm{C}$.

usual primary creep stage. Figure 8 shows the creep rate curve of cast Haynes 282 alloy at $750^{\circ} \mathrm{C}$; stationary and tertiary stages are clearly indicated. The tertiary stage occurred earlier than usual, with a short stationary creep stage. Sajjadi et al. [10] investigated a similar superalloy and reported that the increase in the creep rate was caused not by coarsening of the $\gamma^{\prime}$-phase, but by the change in the $\gamma^{\prime}$-shape from cuboidal to globular. However, the TEM images in 


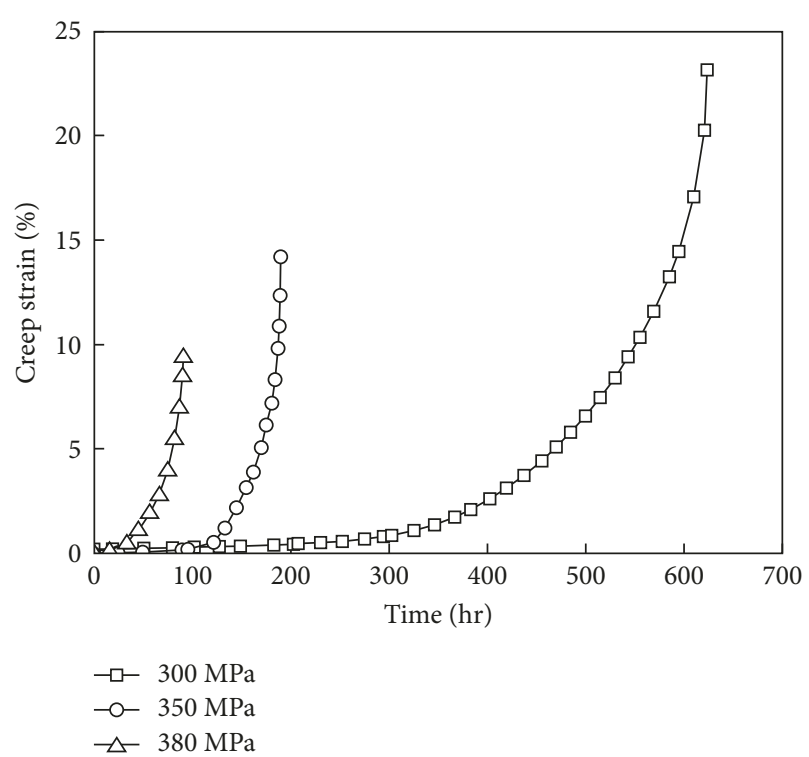

Figure 7: Creep curves of cast Haynes 282 alloy at $750^{\circ} \mathrm{C}$.

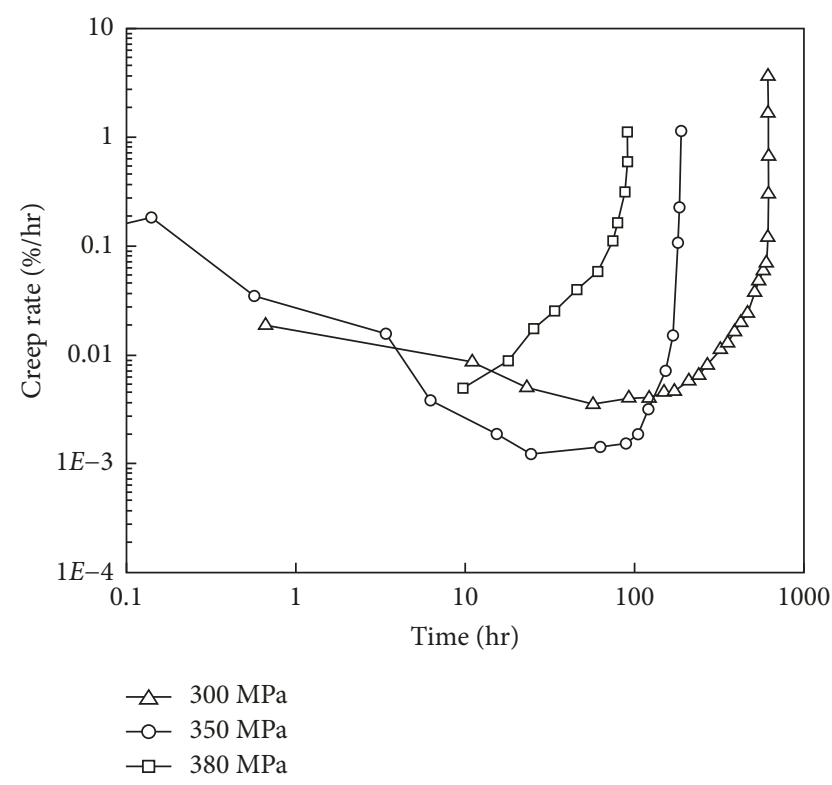

Figure 8: Creep rate as a function of time for cast Haynes 282 alloy at $750^{\circ} \mathrm{C}$.

Figure 9 show homogeneously distributed $\gamma^{\prime}$-particles with a globular shape in the cast alloy before creep, so the results of Sajjadi et al. [10] are not applicable to this study. The average size of the precipitates was $39 \mathrm{~nm}$, which is smaller than that reported by Matysiak et al. [5] (70-110 nm), who investigated the same alloy directly after thin-walled wedge permanent casting in which coarsening of $\gamma^{\prime}$-particles occurred. In this study, however, $\gamma^{\prime}$-particles fully dissolved during solution treatment after casting; a dense precipitation of finely distributed $\gamma^{\prime}$-particles formed during the two-step ageing treatment following by quenching. The creep test in this study was performed under relatively high stress, allowing dislocations to slip easily past small obstacles such

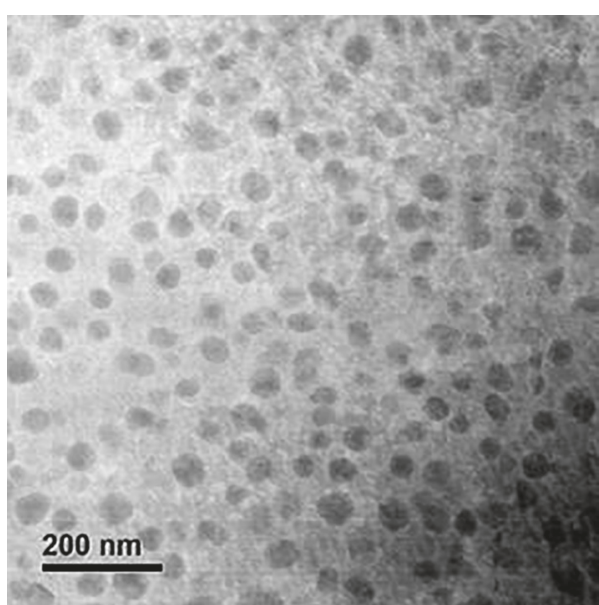

FIgURE 9: Transmission electron microscopy (TEM) image showing $\gamma^{\prime}$ particles of Haynes 282 alloy aged for $8 \mathrm{~h}$.

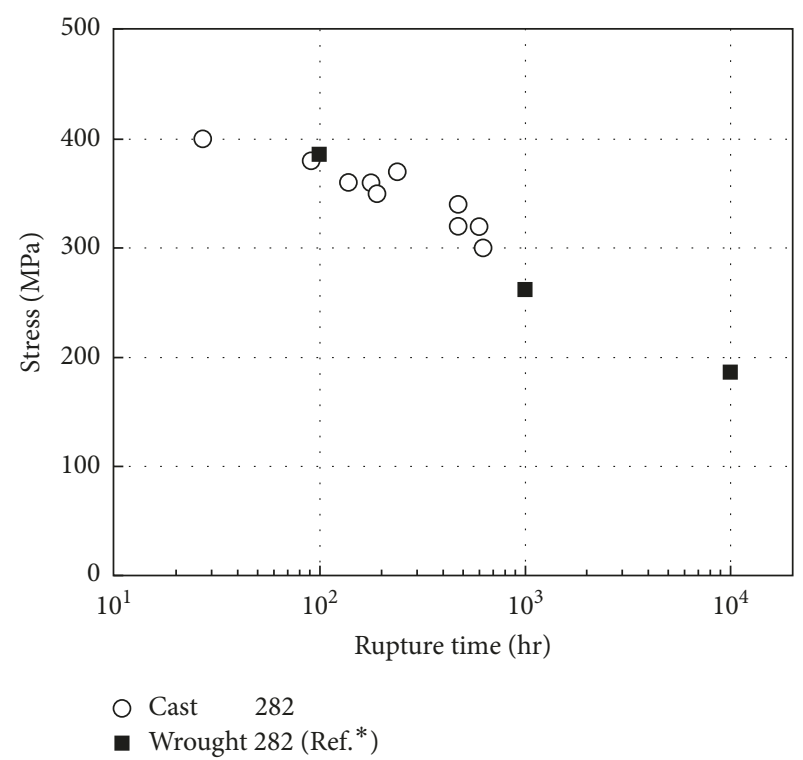

FIGURE 10: Creep rupture life versus stress of Haynes 282 wrought and cast alloys.

as $\gamma^{\prime}$-particles, which should have resulted in earlier softening and tertiary creep. The tensile stress of cast Haynes 282 alloy is $498 \mathrm{MPa}$ at $750^{\circ} \mathrm{C}$, and the melting temperature is $1,300-1,375^{\circ} \mathrm{C}$; as such, the homologous temperature (T/Tm) would be $0.62-0.65$. According to the Ashby deformation mechanism map [11], the main mechanisms for creep generation in this investigation were grain boundary diffusional creep.

Figure 10 shows creep rupture test results for cast Haynes 282 alloy compared to that of wrought alloy; the results for wrought alloy were taken from data provided by Haynes International [1]. The creep rupture lifetimes of cast and wrought alloys were similar, which is completely different from the results of the tensile tests. Microdefects, large inclusions, and/or secondary phases in the interdendritic region that markedly reduced the TS of cast alloy may not 


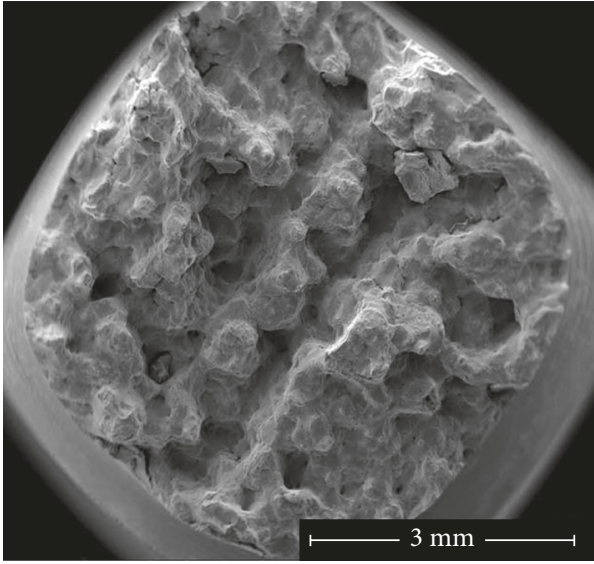

(a)

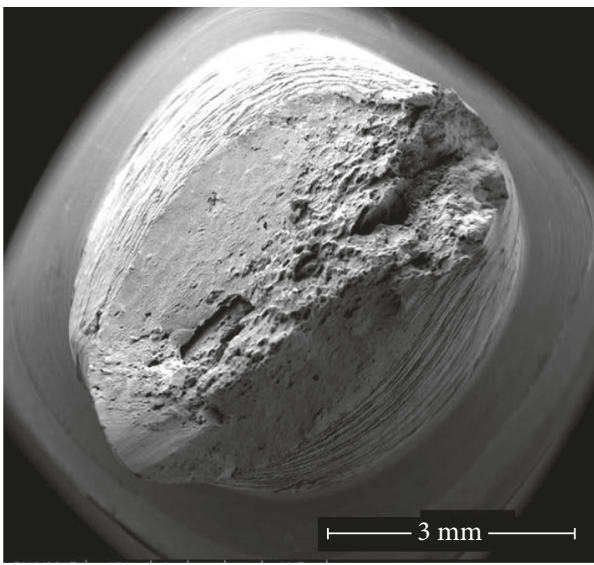

(c)

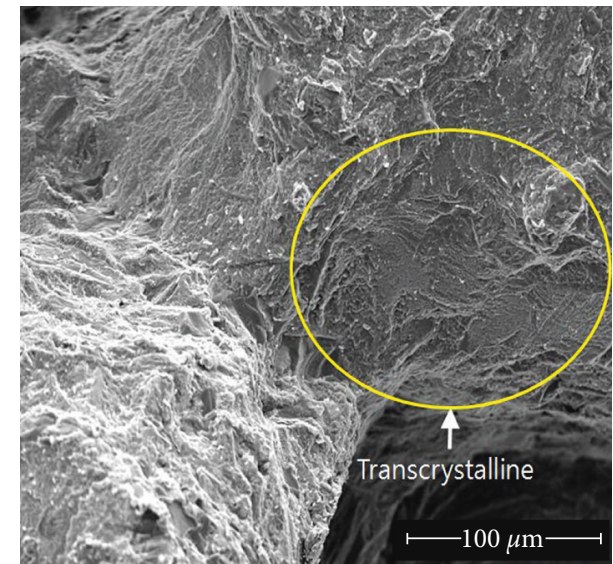

(b)

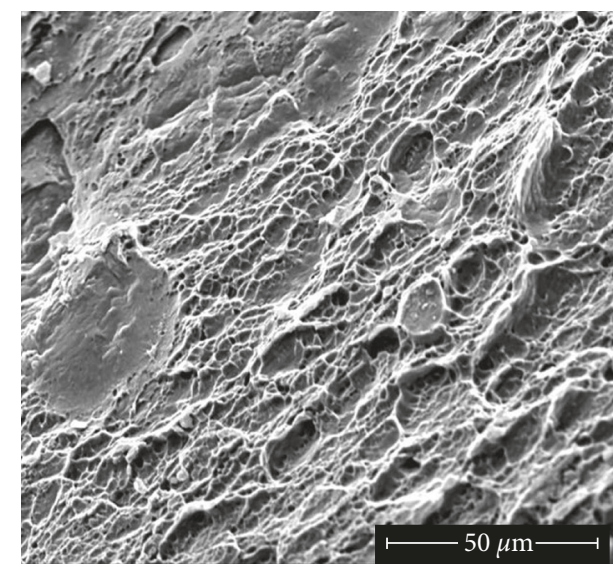

(d)

Figure 11: Fracture surfaces of crept specimens under stresses of $400 \mathrm{MPa}(\mathrm{a}, \mathrm{b})$ and $300 \mathrm{MPa}(\mathrm{c}, \mathrm{d})$.

affect creep rupture life. Haynes 282 alloy is strengthened by two mechanisms: solid-solution strengthening and precipitation strengthening. We used the same alloy and heat treatment to compare cast and wrought alloys. The density and size of $\gamma^{\prime}$-particles were similar (Figure 9), which meant that the alloys responded in a similar manner to the two strengthening mechanisms with regard to creep strength. Under tensile testing, microdefects, large inclusions, and secondary phases, especially in the interdendritic region, could easily act as crack initiation sites via stress concentration; however, such defects did not affect the deformation mechanism during creep under much slower strain rates and lower stress.

Figures 11(a) and 11(b) show that the fracture surface of cast alloy crept under the highest stress of $400 \mathrm{MPa}$ and fractured after the shortest lifetime of $27 \mathrm{~h}$. Figures $11(\mathrm{c})$ and 11(d) show that the fracture surface of cast alloy crept under the lowest stress of $300 \mathrm{MPa}$ and the longest lifetime of $624 \mathrm{~h}$. Figure 11(a) shows that dendrites regularly grew in the longitudinal direction; cracks propagated in the interdendritic region or along the dendrite/interdendrite boundary. Cracks propagated along large secondary phases in the interdendritic region; thus, this region was more brittle than the dendritic region, as shown in Figure 11(b), magnified in
Figure 11(a). The incompatibility of plastic flow between the two regions can manifest under creep stress, which should cause stress concentration at the dendrite/interdendrite boundary or in the interdendritic region where microcavities form and propagate. As indicated by the circle in the fractography image in Figure 11(b), a cleavage-type transcrystalline fracture appeared in the interdendritic region. The fracture behaviour of the sample crept under the lowest creep stress $(300 \mathrm{MPa})$ and the longest lifetime $(624 \mathrm{~h})$ showed a completely different fracture mode. A smooth fracture surface is shown in Figure 11(c); at higher magnification, a large number of grain boundary cavities are evident (Figure 11(d)), which are associated with the intercrystalline fracture mode. The interdendritic region could not be distinguished from the dendritic region dissolved by diffusion during extended creep durations, resulting in a type of grain boundary formation. Cr-carbides and other secondary phases at the grain boundary act as initiation sites of creep cavities, and this is the typical deformation mode of Coble creep [12] via grain boundary diffusion and sliding. Coble reported that grain boundary diffusional creep can occur in the temperature range $\mathrm{T} / \mathrm{Tm}<0.7$ and under intermediate creep stress; this effect is similar to our observations for creep stress lower than $380 \mathrm{MPa}$. Cavities can be 
initiated at the site of grain boundary precipitates through grain boundary sliding and diffusion and propagate by interconnection. Such a fracture mode was also observed in the wrought alloy; however, the cast alloy showed distinctly lower TS and elongation than the wrought alloy, due to earlier crack formation generated at segregations, large secondary phases, and microdefects that remained after casting. The creep rupture strength of the cast alloy was similar to that of the wrought alloy, because such defects and segregations influencing the TS grew out of, or partially dissolved, during creep; thus, their effect was gradually eliminated. The creep deformation mechanism of both alloys during long-duration creep was the same as that of grain boundary diffusional creep; consequently, both alloys showed similar creep rupture strength.

\section{Conclusion}

(1) The TS and elongation of the cast Haynes 282 alloy were much lower than those of the wrought alloy over the test temperature range $25-800^{\circ} \mathrm{C}$, because large particles and the heterogeneous microstructure between dendritic and interdendritic regions of the cast alloy caused earlier crack formation, leading to brittle fracture.

(2) The creep rupture strength of the cast alloy exhibited no difference to that of the wrought alloy, because the inhomogeneous microstructure of the cast alloy between dendritic and interdendritic regions contained secondary particles that dissolved during long-term creep. Creep deformation is caused by the same mechanism, such as grain boundary diffusion and/or grain boundary sliding.

(3) No interior defects were evident in the cast Haynes 282 alloy after casting; thus, the cast alloy can substitute for the wrought alloy under creep loading at $750^{\circ} \mathrm{C}$.

\section{Conflicts of Interest}

The authors declare that they have no conflicts of interest.

\section{Acknowledgments}

This work was supported by the Pukyong National University Research Abroad Fund in 2016 (C-D-2015-0502).

\section{References}

[1] Haynes International, "Haynes 282 alloy," Rep. No. H-3173, Haynes International, Kokomo, IN, USA, 2005.

[2] L. M. Pike, "Long term thermal exposure of Haynes 282 alloy," in Proceedings of the 7th International Symposium on Superalloy 718 and Derivatives, vol. 2, pp. 645-660, Pittsburgh, PA, USA, October 2010.

[3] R. Viswanathan, J. Shingledecker, and J. A. Hawk, "Effect of creep in advanced materials for use in ultra-supercritical coal power plants," in Proceedings of the 2nd International ECCC Conference on Creep and Fracture in High Temperature
Components-Design and Life Assessment, pp. 31-43, DEStech Publications, Inc., Lancaster, UK, 2009.

[4] S. K. Srivastava and J. L. Caron, "Recent developments in the characteristics of HAYNES 282 alloy for use in A-USC applications," in Proceedings of the 7th International Conference, on Advances in Materials Technology for Fossil Power Plants, pp. 120-130, Waikoloa, HI, USA, October 2013.

[5] H. Matysiak, M. Zagorska, J. Andersson et al., "Microstructure of Haynes superalloy after vacuum induction melting and investment casting of thin-walled components," Materials, vol. 6, no. 11, pp. 5016-5037, 2013.

[6] R. W. Kozar, A. Suzuki, W. W. Milligan, J. J. Schirra, M. F. Savage, and T. M. Pollock, "Strengthening mechanisms in polycrystalline multimodal nickel-base superalloys," Metallurgical and Materials Transactions A, vol. 40, no. 7, pp. 1588-1603, 2009.

[7] I. S. Kim and B. G. Choi, "Mechanisms of tensile and creep deformation at elevated temperatures in a Ni-base superalloy alloy 263," Korean Journal of Metals and Materials, vol. 49, no. 7, pp. 535-540, 2011.

[8] S. Takeuchi and E. Kuramoto, "Temperature and orientation dependence of the yield stress in Ni\{in3\} Ga single crystals," Acta Metallurgica, vol. 21, no. 4, pp. 415-425, 1973.

[9] V. Paidar, D. P. Pope, and V. Vitek, "A theory of the anomalous yield behavior in $\mathrm{L}_{2}$ ordered alloys," Acta Metallurgica, vol. 32, no. 3, pp. 435-448, 1984.

[10] S. A. Sajjadi, S. Nategh, and R. I. L. Guthrie, "Study of microstructure and mechanical properties of high performance Ni-base superalloy GTD-111," Materials Science and Engineering $A$, vol. 325, no. 1-2, pp. 484-489, 2002.

[11] H. J. Frost and M. F. Ashby, Deformation Mechanism Maps, Pergamon Press, Elmsford, NY, USA, 1982.

[12] R. L. Coble, "A model for boundary diffusion controlled creep in polycrystalline materials," Journal of Applied Physics, vol. 34, no. 6, pp. 1679-1682, 1963. 


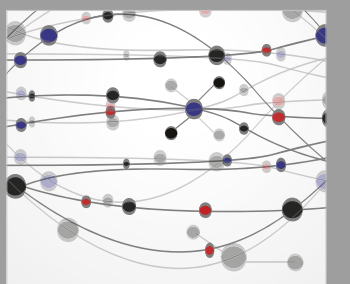

The Scientific World Journal
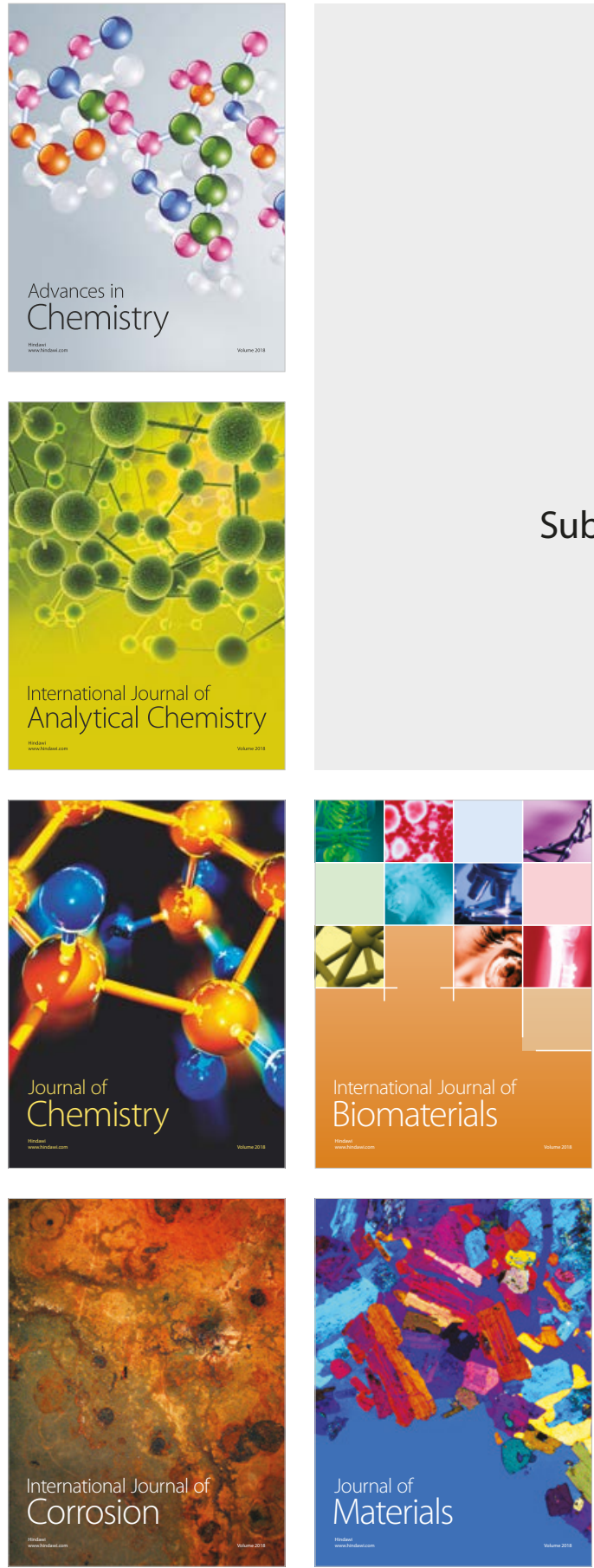

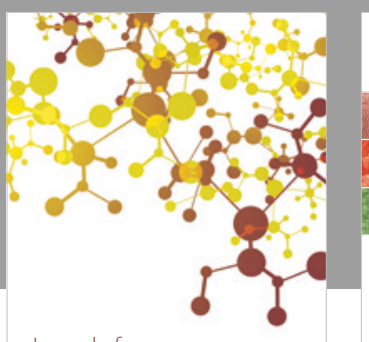

Journal of

Applied Chemistry
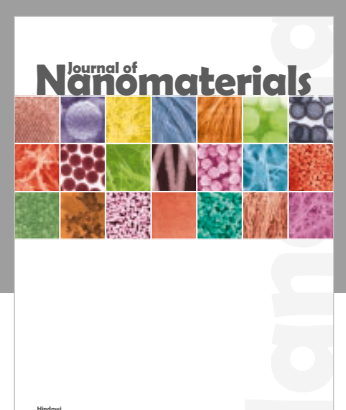

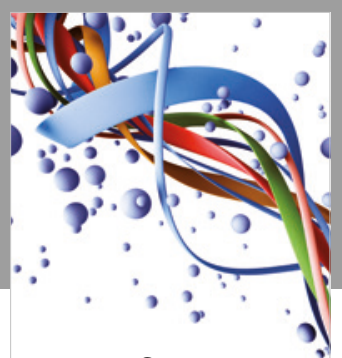

Scientifica

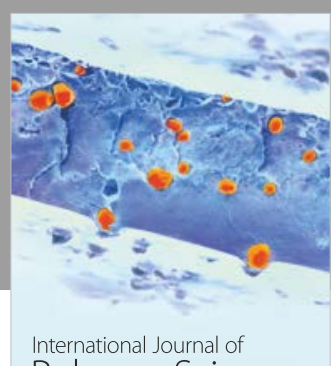

Polymer Science

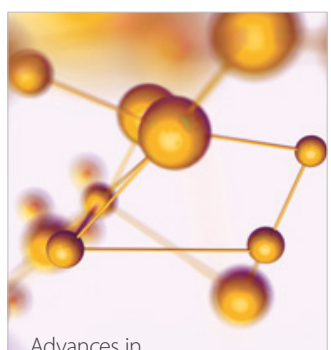

Physical Chemistry
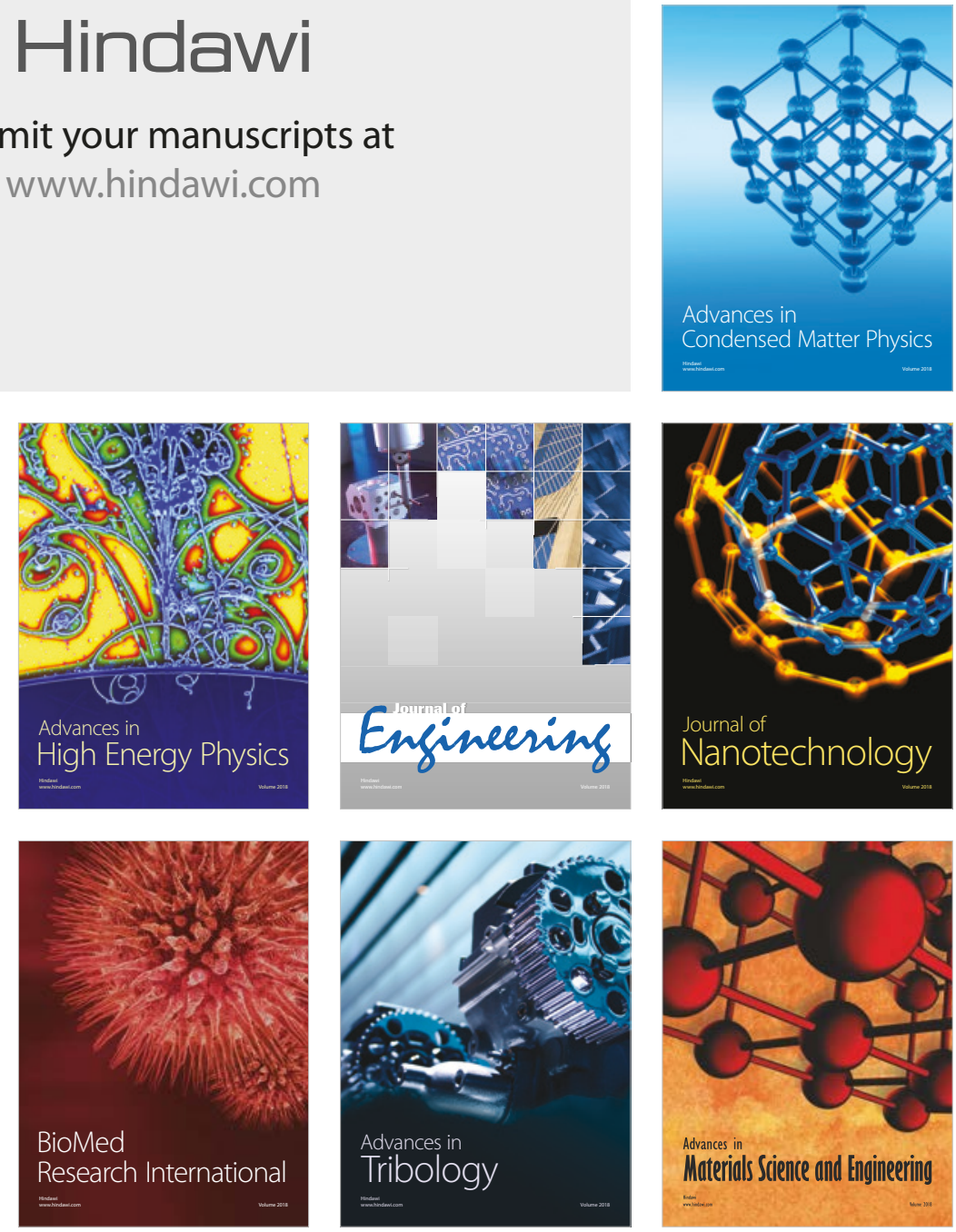